\title{
Implied Bond and Derivative Prices Based on Non-Linear Stochastic Interest Rate Models
}

\author{
Ghulam Sorwar ${ }^{1}$, Sharif Mozumder ${ }^{2}$ \\ ${ }^{1}$ Nottingham University Business School, Jubilee Campus, Nottingham, UK \\ ${ }^{2}$ Department of Mathematics, University of Dhaka, Dhaka, Bangladesh \\ E-mail:ghulam.sorwar@nottingham.ac.uk,sharif_math2000@yahoo.com \\ Received March 8, 2010; revised April 2, 2010; accepted April 30, 2010
}

\begin{abstract}
In this paper we expand the Box Method of Sorwar et al. (2007) to value both default free bonds and interest rate contingent claims based on one factor non-linear interest rate models. Further we propose a one-factor non-linear interest rate model that incorporates features suggested by recent research. An example shows the extended Box Method works well in practice.
\end{abstract}

Keywords: Stochastic, Interest Rates, Derivatives, Box Method

\section{Introduction}

Stochastic differential equations are the foundations on which modern option pricing methodology is based. However, non-linear stochastic differential equations for interest rate models have been proposed that captures the non-linear dynamics of the spot interest rates. There are two aspects to the modeling of interest rate term structure models and interest rate contingent claims. The first concerns the econometric aspects (see for example, [1]) and the second the numerical implementation of the resulting models. With regard to the numerical aspects of interest rate modeling, there exist three different approaches. The first is the lattice approach introduced by Cox-Ross-Rubinstein (1979) [2]. However, as Barone-Adesi, Dinenis and Sorwar (1997) [3] have demonstrated the lattice approach does not always lead to meaningful bond and hence contingent claim prices. The second approach is the Monte-Carlo simulation approach introduced by Boyle (1977) is mainly used to value path dependent European type contingent claims. To date no single accepted Monte-Carlo simulation scheme has been put forward for the valuation of American type contingent claims. The third approach is the partial differential equation (PDE) approach. With this approach, the partial first and second order derivatives are discretized to produce a system of equations which are then solved iteratively to obtain the bond and contingent claim prices. However, Sorwar et al. (2007) have shown that the usual finite difference approach used to discretize the PDE does not always lead to bond and contingent claim prices that correspond with analytical prices where these prices are available.

Sorwar et al. (2007) introduced the Box Method from engineering to improve on the standard finite difference approach. Sorwar et al. (2007) focused on the CKLS (1992) model. Sorwar et al. (2007) did not attempt to value bonds and contingent claims based on non-linear interest rate models. Ait-Sahalia (1996) [4] non-and Conley et al. (1997) [5] propose parametric linear one-factor which allows non-linear parameterisation. Our main objective in this paper is to expand the Box Method of Sorwar et al. (1997) to price bonds and contingent claims based on both linear and non-linear interest rate models.

The outline of the paper is as follows: Section 2 the general non-linear parametric model and the resulting partial differential equation for default free bonds and contingent claims is outlined. We then derive the Expanded Box Method (EBM) for the valuation of default free bonds and contingent claims. Using US estimates we compute implied bond and contingent claims prices in Section 3. Section 4 contains a summary and conclusion.

\section{Expanded Box Method (EBM)}

In this section we discuss the valuation of the bond and contingent claim prices based on the extended Ait-Sahalia (1996) [4] and Conley et al. (1997) [5] framework. Following Sorwar et al. (2007) we let:

$$
B\left(r_{t}, t, T^{*}\right): \text { price of a discount bond at time } t \text { which }
$$


Table 1. Iternative Parametric Specifications of the Spot Interest Rate Process $d r_{t}=\mu\left(r_{t}\right) d t+\sigma^{2}\left(r_{t}\right) d W_{t}$.

\begin{tabular}{ccc}
\hline $\begin{array}{c}\text { Drift function } \\
\mu(r)\end{array}$ & $\begin{array}{c}\text { Diffusion function } \\
\sigma^{2}(r)\end{array}$ & Reference \\
\hline$\alpha_{0}+\alpha_{1} r$ & $\beta_{0}$ & Vasicek (1977) [6] \\
$\alpha_{0}+\alpha_{1} r$ & $\beta_{1} r$ & $\begin{array}{c}\text { Cox-Ingersoll-Ross(1985) [7] } \\
\text { Brown-Dybvig(1986) [8] } \\
\text { Gibbons-Ramaswamy(1993) [9] }\end{array}$ \\
$\alpha_{0}+\alpha_{1} r$ & $\beta_{2} r^{2}$ & Courtadon (1982) [10] \\
$\alpha_{0}+\alpha_{1} r$ & $\beta_{2} r^{\beta_{3}}$ & Chen et al. (1992) \\
$\alpha_{0}+\alpha_{1} r+\alpha_{2} r^{2}+\frac{\alpha_{3}}{r}$ & $\beta_{0}+\beta_{1} r+\beta_{2} r^{\beta_{3}}$ & Ait-Sahalia (1996) [4] \\
$\alpha_{0}+\alpha_{1} r+\alpha_{2} r^{\alpha_{3}}+\frac{\alpha_{4}}{r^{\alpha_{5}}}$ & $\beta_{0}+\beta_{1} r+\beta_{2} r^{\beta_{3}}$ &
\end{tabular}

matures at time $T^{*}$ with the generated spot rate $r_{t}$.

$P\left(t, T^{*}, T\right)$ : price of a contingent claim at time $t$ which expires at time $T$ based on a discount bond which matures at time $T^{*}$ subject to suitable boundary conditions.

In a risk-neutral world, the drift rate is adjusted by the market price of risk $\lambda r^{1}$ so that the short-term interest process becomes:

$$
\begin{gathered}
d r_{t}=\left(\alpha_{0}+\left(\alpha_{1}+\lambda\right) r+\alpha_{2} r^{\alpha_{3}}+\alpha_{4} r^{-\alpha_{5}}\right) d t+ \\
\sqrt{\beta_{0}+\beta_{1} r+\beta_{2} r^{\beta_{3}}} d W_{t}
\end{gathered}
$$

The resulting partial differential equation is:

$$
\begin{aligned}
& \frac{1}{2}\left[\beta_{0}+\beta_{1} r+\beta_{2} r^{\beta_{3}}\right] \frac{\partial^{2} U}{\partial r^{2}} \\
& +\left[\alpha_{0}+\left(\alpha_{1}+\lambda\right) r+\alpha_{2} r^{\alpha_{3}}+\alpha_{4} r^{-\alpha_{5}}\right] \frac{\partial U}{\partial r}-r U+\frac{\partial U}{\partial t}=0
\end{aligned}
$$

In equation (2) $U\left(r_{t}, t\right)$ may represent either $B\left(r_{t}, t, T^{*}\right)$ or $P\left(t, T^{*}, T\right)$ subject to the appropriate boundary conditions (see [10] for more details). Following Sorwar et al. (2007) we transform the above pricing equation such that either the bond or the contingent claims evolves from the options expiration date or the bonds maturity date to the present, i.e. we let $\tau=T-t$.

${ }^{1}$ Risk premium is treated differently by researchers. Vasicek (1977) [6] takes $\lambda(r)=\lambda$, Chan et al. (1992) [1] take $\lambda(r)=0$, ox et al. (1985), we take $\lambda(r)=\lambda r$.
The above equation then becomes:

$$
\begin{gathered}
\frac{\partial^{2} U}{\partial r^{2}}+2\left[\frac{\alpha_{0}+\left(\alpha_{1}+\lambda\right) r+\alpha_{2} r^{\alpha_{3}}+\alpha_{4} r^{-\alpha_{5}}}{\beta_{0}+\beta_{1} r+\beta_{2} r^{\beta_{3}}}\right] \frac{\partial U}{\partial r}- \\
\frac{2 r}{\beta_{0}+\beta_{1} r+\beta_{2} r^{\beta_{3}}} U=\frac{2}{\beta_{0}+\beta_{1} r+\beta_{2} r^{\beta_{3}}} \frac{\partial U}{\partial \tau}
\end{gathered}
$$

We now choose a general function $R(r, \alpha, \beta)$ such that:

$$
\begin{aligned}
& \frac{1}{R} \frac{\partial}{\partial r}\left[R \frac{\partial U}{\partial r}\right]=\frac{\partial^{2} U}{\partial r^{2}}+ \\
& 2\left[\frac{\alpha_{0}+\left(\alpha_{1}+\lambda\right) r+\alpha_{2} r^{\alpha_{3}}+\alpha_{4} r^{-\alpha_{5}}}{\beta_{0}+\beta_{1} r+\beta_{2} r^{\beta_{3}}}\right] \frac{\partial U}{\partial r}
\end{aligned}
$$

The above expression simplifies to yield:

$$
\frac{1}{R} \frac{\partial R}{\partial r}=2\left[\frac{\alpha_{0}+\left(\alpha_{1}+\lambda\right) r+\alpha_{2} r^{\alpha_{3}}+\alpha_{4} r^{-\alpha_{5}}}{\beta_{0}+\beta_{1} r+\beta_{2} r^{\beta_{3}}}\right]
$$

We now integrate from the general value $r$ $\left(r_{n-1}<r<r_{n+1}\right)$ to the lower limit of integration $r=0$ to obtain:

$$
\begin{aligned}
& R(r, \alpha, \beta)= \\
& \exp \left\{\phi+2 \int_{r_{n-1}}^{r}\left[\frac{\alpha_{0}+\left(\alpha_{1}+\lambda\right) r+\alpha_{2} r^{\alpha_{3}}+\alpha_{4} r^{-\alpha_{5}}}{\beta_{0}+\beta_{1} r+\beta_{2} r^{\beta_{3}}}\right] d r\right\}
\end{aligned}
$$

where $\phi=\ln R(0, \alpha, \beta)$. We further note that:

$$
\frac{1}{R} \frac{\partial}{\partial r}\left[R \frac{\partial U}{\partial r}\right]=\frac{1}{Q} \frac{\partial}{\partial r}\left[Q \frac{\partial U}{\partial r}\right]
$$

where: 


$$
\begin{aligned}
& Q(r, \alpha, \beta)= \\
& \exp \left\{2 \int_{0}^{r}\left[\frac{\alpha_{0}+\left(\alpha_{1}+\lambda\right) r+\alpha_{2} r^{\alpha_{3}}+\alpha_{4} r^{-\alpha_{5}}}{\beta_{0}+\beta_{1} r+\beta_{2} r^{\beta_{3}}}\right] d r\right\}
\end{aligned}
$$

So equation (3) becomes:

$$
\begin{gathered}
\frac{1}{Q} \frac{\partial}{\partial r}\left(Q \frac{\partial U}{\partial r}\right)-\frac{2 r}{\beta_{0}+\beta_{1} r+\beta_{2} r^{\beta_{3}}} U=\quad \text { This leads to the transformation of equation (6) as: } \\
\frac{1}{Q(s)} \frac{\partial}{\partial s}\left(\Psi(s) \frac{\partial U}{\partial s}\right)-\frac{2 s}{c^{2}(1-s)^{3}} \frac{U}{\beta_{0}+\frac{\beta_{1} s}{c(1-s)}+\beta_{2}\left[\frac{s}{c(1-s)}\right]^{\beta_{3}}}=\frac{2}{c(1-s)^{2}} \frac{1}{\beta_{0}+\frac{\beta_{1} s}{c(1-s)}+\beta_{2}\left[\frac{s}{c(1-s)}\right]^{\beta_{3}} \frac{\partial U}{\partial \tau}}
\end{gathered}
$$

where:

$$
\begin{aligned}
& \Psi(s)=c(1-s)^{2} Q(s) \\
& Q(s)=\exp \left\{\int_{0}^{s} \frac{2}{c(1-s)^{2}}\left\{\frac{\alpha_{0}+\frac{\left(\alpha_{1}+\lambda\right) s}{c(1-s)}+\alpha_{2}\left[\frac{s}{c(1-s)}\right]^{\alpha_{3}}+\alpha_{4}\left[\frac{s}{c(1-s)}\right]^{-\alpha_{5}}}{\beta_{0}+\frac{\beta_{1} s}{c(1-s)}+\beta_{2}\left[\frac{s}{c(1-s)}\right]^{\beta_{3}}}\right\} d r\right\}
\end{aligned}
$$

Following the set-up of Sorwar et al. (2007) a grid of size $M \times N$ is constructed for values of $U_{n}^{m}=U(n \Delta r, m \Delta t)$ - the value of $U$ at time increment $t_{m}$ and interest rate increment $s_{n}$, for each method, where:

$$
\begin{gathered}
t_{m}=t_{0}+m \Delta t \quad m=0,1, \ldots, M \\
{ }^{2} \Delta s_{n+1}=\Delta s_{n}+a \quad n=1, \ldots, N
\end{gathered}
$$

where $a$ is an arbitrary constant.

rivative gives: $\frac{\partial U}{\partial \tau}=\frac{U-U_{0}}{\Delta t}$

where $U_{0}$ and $U$ refers to bond or contingent claims prices at time step $m-1$ and $m$ respectively.

Integrating equation (8) from the point $s_{n-\frac{1}{2}}=\frac{s_{n}+s_{n-1}}{2}$ to point $s_{n+\frac{1}{2}}=\frac{s_{n+1}+s_{n}}{2}$, we have:

Using the Euler backward difference for the time de-

$$
\begin{aligned}
& -\Delta t \int_{s=\frac{1}{2}}^{s} \frac{\partial}{\partial s}\left(\Psi(s) \frac{\partial U}{\partial s}\right) d s+2 \Delta t \int_{s_{n-\frac{1}{2}}}^{s} \frac{s}{c^{2}(1-s)^{3}} Q(s) f(s) U d s+2 \int_{s_{n-\frac{1}{2}}}^{s} \frac{1}{c(1-s)^{2}} Q(s) f(s) U d s \\
& =2 \int_{s_{n-\frac{1}{2}}}^{s} \frac{1}{c(1-s)^{2}} Q(s) f(s) U_{0} d s
\end{aligned}
$$

Discretizing each of the above integrals, and rearranging gives us the following matrix equation:

$$
\alpha_{n} U_{n}^{m-1}=\chi_{n} U_{n-1}^{m}+\eta_{n} U_{n}^{m}+\beta_{n} U_{n+1}^{m}
$$

where:

\footnotetext{
${ }^{2}$ Where $a$ and $\Delta s_{0}$ are arbitrary constants. A derivation of this expression can be found in Settari and Aziz (1972) [11].
} 


$$
\begin{aligned}
& 2 \int_{s-\frac{1}{2}}^{s+\frac{1}{2}} \frac{1}{c(1-s)^{2}} Q(s) f(s) U d s \\
= & 2 \int_{s-\frac{1}{2}}^{s+\frac{1}{2}} \frac{1}{c(1-s)^{2}} Q(s) f(s) U_{0} d s
\end{aligned}
$$

Discretizing each of the above integrals, and rearranging gives us the following matrix equation:

$$
\alpha_{n} U_{n}^{m-1}=\chi_{n} U_{n-1}^{m}+\eta_{n} U_{n}^{m}+\beta_{n} U_{n+1}^{m}
$$

where:

$$
\begin{aligned}
& \alpha_{n}=2 I_{1} \\
& \chi_{n}=\frac{-\Delta t}{s_{n}-s_{n-1}} \frac{\Psi\left(s_{n-\frac{1}{2}}\right)}{Q\left(s_{n}\right)} \\
& \beta_{n}=\frac{-\Delta t}{s_{n+1}-s_{n}} \frac{\Psi\left(s_{n+\frac{1}{2}}\right)}{Q\left(s_{n}\right)} \\
& \eta_{n}=\frac{\Delta t}{s_{n}-s_{n-1}} \frac{\Psi\left(s_{n-\frac{1}{2}}\right)}{Q\left(s_{n}\right)}+\frac{\Delta t}{s_{n+1}-s_{n}} \frac{\Psi\left(s_{n+\frac{1}{2}}\right)}{Q\left(s_{n}\right)}+2 \Delta t I_{0}+2 I_{1} \\
& I_{0}=\frac{s_{n} f\left(s_{n}\right)}{c^{2}\left(1-s_{n}\right)^{3}}\left(s_{n+\frac{1}{2}}-s_{n-\frac{1}{2}}\right) \\
& I_{1}=\frac{f\left(s_{n}\right)}{c\left(1-s_{n}\right)^{2}}\left(s_{n+\frac{1}{2}}-s_{n-\frac{1}{2}}\right)
\end{aligned}
$$

The matrix equation linking all bond prices or contingent claim prices between two successive time steps $m-1$ and $m$ is:

$$
\begin{gathered}
\left(\begin{array}{c}
\alpha_{0} U_{1}^{m-1} \\
\alpha_{0} U_{1}^{m-1} \\
\vdots \\
\vdots \\
\vdots \\
\vdots \\
\alpha_{N} U_{N}^{m-1}
\end{array}\right)= \\
\\
\left(\begin{array}{ccccccc}
\eta_{1} & \beta_{1} & 0 & 0 & 0 & \cdots & 0 \\
\chi_{2} & \eta_{2} & \beta_{2} & 0 & 0 & \cdots & 0 \\
0 & \chi_{3} & \eta_{3} & \beta_{3} & 0 & \cdots & 0 \\
\cdots & \ddots & \ddots & \ddots & \ddots & \ddots & \vdots \\
\vdots & \ddots & \ddots & \chi_{N-3} & \chi_{N-3} & \beta_{N-3} & 0 \\
\vdots & \ddots & \ddots & 0 & \chi_{N-2} & \eta_{N-2} & \beta_{N-2} \\
0 & \cdots & \cdots & 0 & 0 & \chi_{N-1} & \eta_{N-1}
\end{array}\right)\left(\begin{array}{c}
\alpha_{0} U_{1}^{m} \\
\alpha_{0} U_{1}^{m} \\
\vdots \\
\vdots \\
\vdots \\
\vdots \\
\alpha_{N} U_{N-1}^{m}
\end{array}\right)
\end{gathered}
$$

Sorwar et al. [12] used the following SOR iteration process to determine bond and contingent claims prices:

$$
z_{n}^{m}=\frac{1}{\eta_{n}}\left(\alpha_{n} U_{n}^{m-1}-\chi_{n} U_{n-1}^{m}-\beta_{n} U_{n+1}^{m-1}\right)
$$

In particular they evaluated bond using the following expression:

$$
U_{n}^{m}=\omega z_{n}^{m}+(1-\omega) U_{n}^{m-1}
$$

Contingent claims were calculated using:

$$
U_{n}^{m}=\max \left[Z, \omega z_{n}^{m}+(1-\omega) U_{n}^{m-1}\right]
$$

where $\mathrm{Z}$ is the intrinsic value of the contingent claim and for $\mathrm{n}=1, \ldots \ldots, \mathrm{N}-1$, and $\omega \in(1,2]^{3}$.

\section{Analysis of Results}

In this section we apply the EBM using recent estimates of the non-linear model of Ait-Sahalia (1996) [4] on 7-day Eurodollar deposit spot rate over 1973-1995 to demonstrate the method. Ait-Sahalia (1996, Table 4) [4] obtained the following estimates:

$$
\begin{gathered}
\alpha_{0}=-4.643 \times 10^{-3}, \alpha_{1}= \\
4.333 \times 10^{-2}, \alpha_{2}=-1.143 \times 10^{-1}, \alpha_{3}=2, \\
\alpha_{4}=1.304 \times 10^{-4}, \alpha_{5}=1 . \\
\beta_{0}=1.108 \times 10^{-4}, \beta_{1}= \\
-1.883 \times 10^{-3}, \beta_{2}=9.681 \times 10^{-3}, \beta_{3}=2.073
\end{gathered}
$$

Table 2 reports the bond prices for maturities ranging from 6 months to 30 years and across interest rates of $2 \%$ to $16 \%$. Table III reports both the value of call and put options across a wide range of interest rates. We consider both short and long dated call and put options. The short dated call and put options are based on a 5-year bond with an expiry date of 1 year and is during the last year before the bond matures. Similarly long dated options are based on 10-year bond with an expiry date of 5 years during the last 5 years of the bond. Finally both call and put option prices are calculated across a wide range of exercise prices. The exercise prices are chosen so as to highlight variation of prices for both in-the-money and out-of-the-money options. We assume $\lambda$, the market price of risk is zero.

Turning to Table 2, we find that at lower interest rate bond prices decay slowly as the term to maturity increases. For example, at $2 \%$ interest rate a 1 year maturity bond is valued at 98.1119 , whilst a 30 year bond is valued at 74.8290 . At high interest rates, the bond price decay is more rapid for example at $16 \%$ interest rate, a 1 year maturity bond is valued at 85.2915 , whist a 30 year maturity bond is valued at 1.1770 . Turning to Table 3, we observe the following features. Short expiry call op

\footnotetext{
${ }^{3} \omega$ is determined by numerical experimentation. For all our calculations we took $\omega=1.85$
} 
Table 2. All options written on zero coupon bonds with a face value of $\$ \mathbf{1 0 0 . 0 0}$.

\begin{tabular}{ccccccccc}
\hline & \multicolumn{7}{c}{ Interest Rate } \\
\hline $\begin{array}{c}\text { Maturity } \\
\text { of Bond } \\
0.5\end{array}$ & $\mathbf{2 \%}$ & $\mathbf{4 \%}$ & $\mathbf{6 \%}$ & $\mathbf{8 \%}$ & $\mathbf{1 0 \%}$ & $\mathbf{1 2 \%}$ & $\mathbf{1 4 \%}$ & $\mathbf{1 6 \%}$ \\
1 & 99.0286 & 98.0370 & 96.9855 & 96.0885 & 95.1315 & 94.1844 & 93.2506 & 92.3403 \\
5 & 98.1119 & 96.1434 & 94.0805 & 92.3406 & 90.5050 & 88.7059 & 86.9566 & 85.2915 \\
& 92.2400 & 83.3035 & 74.3413 & 67.4685 & 60.8623 & 54.9010 & 49.7324 & 45.6212 \\
10 & 87.0431 & 71.9535 & 56.7017 & 46.1717 & 37.2750 & 30.1193 & 24.7834 & 21.3038 \\
15 & 83.1089 & 64.1538 & 44.6651 & 32.1800 & 22.9491 & 16.5267 & 12.3933 & 10.1317 \\
20 & 79.9228 & 58.6473 & 36.4723 & 22.9644 & 14.3178 & 9.0809 & 6.2237 & 4.8889 \\
25 & 77.2156 & 54.6338 & 30.8731 & 16.8832 & 9.0110 & 5.0032 & 3.1400 & 2.3870 \\
30 & 74.8290 & 51.6021 & 27.0075 & 12.8582 & 5.7491 & 2.7679 & 1.5921 & 1.1770 \\
\hline
\end{tabular}

Table 3. All options written on zero coupon bonds with a face value of $\$ \mathbf{1 0 0 . 0 0}$.

\begin{tabular}{|c|c|c|c|c|c|c|}
\hline$r(\%)$ & $\begin{array}{l}\text { Exercise- } \\
\text { Price }\end{array}$ & $\begin{array}{c}5 \text { year ma- } \\
\text { turity } \\
1 \text { year ex- } \\
\text { piry }\end{array}$ & $\begin{array}{c}5 \text { year ma- } \\
\text { turity } \\
1 \text { year ex- } \\
\text { piry }\end{array}$ & $\begin{array}{c}\text { Exercise- } \\
\text { Price }\end{array}$ & $\begin{array}{c}10 \text { year } \\
\text { maturity } \\
5 \text { year ex- } \\
\text { piry }\end{array}$ & $\begin{array}{c}10 \text { year } \\
\text { maturity } \\
5 \text { year ex- } \\
\text { piry }\end{array}$ \\
\hline & $(83.3035)$ & call & put & (71.9535) & call & put \\
\hline \multirow[t]{6}{*}{4} & 70 & 16.0031 & 0.0000 & 60 & 21.9713 & 0.0007 \\
\hline & 75 & 11.1959 & 0.0000 & 65 & 17.8062 & 0.0493 \\
\hline & 80 & 6.3895 & 0.0050 & 70 & 13.6418 & 0.6489 \\
\hline & 85 & 1.9369 & 1.6966 & 75 & 9.5270 & 3.1894 \\
\hline & 90 & 0.1421 & 6.6966 & 80 & 5.7979 & 8.0466 \\
\hline & (67.4685) & & & (46.1717) & & \\
\hline \multirow[t]{5}{*}{8} & 55 & 16.6811 & 0.0000 & 35 & 22.5578 & 0.0000 \\
\hline & 60 & 12.0641 & 0.0000 & 40 & 19.1843 & 0.0000 \\
\hline & 65 & 7.4471 & 0.0000 & 45 & 15.8109 & 0.0058 \\
\hline & 70 & 2.8302 & 2.5315 & 50 & 12.4375 & 3.8283 \\
\hline & 75 & 0.0203 & 7.5315 & 55 & 9.0641 & 8.8283 \\
\hline \multirow[t]{6}{*}{12} & (54.9010) & & & (30.1193) & & \\
\hline & 45 & 14.9341 & 0.0000 & 20 & 19.1395 & 0.0000 \\
\hline & 50 & 10.4996 & 0.0000 & 25 & 16.3942 & 0.0000 \\
\hline & 55 & 6.0652 & 0.1561 & 30 & 13.6492 & 0.0183 \\
\hline & 60 & 1.6310 & 5.1561 & 35 & 10.9042 & 4.8804 \\
\hline & 65 & 0.0000 & 10.1561 & 40 & 8.1591 & 9.8804 \\
\hline \multirow[t]{6}{*}{16} & (45.6212) & & & (21.3038) & & \\
\hline & 35 & 15.7692 & 0.0000 & 10 & 16.7416 & 0.0000 \\
\hline & 40 & 11.5046 & 0.0000 & 15 & 14.4606 & 0.0000 \\
\hline & 45 & 7.2400 & 0.0005 & 20 & 12.1795 & 0.0001 \\
\hline & 50 & 2.9755 & 4.3788 & 25 & 9.8985 & 3.6962 \\
\hline & 55 & 0.0129 & 9.3782 & 30 & 7.6174 & 8.6962 \\
\hline
\end{tabular}

tions decay faster than longer expiry call options; for example at $r=4 \%$; the price of a call option decreases from 16.0031 to 11.1959 when the exercise price in creases from 70 to 75 . For a similar 5 year call option the price decreases from 21.9713 to 17.8062 , when the exercise price increases from 60 to 65 . Furthermore, the call option prices decrease at a slower rate at high interests. This feature becomes more pronounced for longer expiry call options. With regard to put options we find, the prices are very close to zero, when the options are at-themoney or out-of-the-money. Finally, we find that the value of in-the-money put options is dominated by the intrinsic-value.

\section{Conclusions}

The introduction of non-linear stochastic interest rate models has led to the possibility of valuing interest contingent claims that reflects the characteristics of the yield curve more accurately. In this paper we have expanded the Box Method to value both bond and American type interest rate contingent claims based on single factor non-linear interest rate models. We have found that the 
Expanded Box Method works well with the example considered.

\section{References}

[1] K. C. Chan, G. A. Karolyi, F. A. Longstaff and A. B. Sanders, "An Empirical Comparison of Alternative Models of the Short-Term Interest Rate," Journal of Finance, Vol. 47, No. 3, 1992, pp. 1209-1227.

[2] J. C. Cox and S. A. Ross, "Option Pricing: A Simplified Approach," Journal of Financial Economics, Vol. 7, No. 3, 1979, pp. 229-264.

[3] G. Barone-Adesi, E. Dinenis and G. Sorwar, “A Note on the Convergence of Binomial Approximations for Interest Rate Models," Journal of Financial Engineering, Vol. 6, No. 1, 1997, pp. 71-78.

[4] Y. Ait-Sahalia and Y. Testing "Continuous-Time Models of the Spot Interest Rate," Review of Financial Studies, Vol. 9, No. 2, 1996, pp. 385-426.

[5] T. G. Conley, L. P. Hansen, E. G. J. Luttmer and J. A. Scheinkman, "Short-Term Interest Rates as Subordinated Diffusions," Review of Financial Studies, Vol. 10, No. 3, 1997, pp. 525-577.
[6] O. A. Vasicek, "An Equilibrium Characterization of the Term Structure," Journal of Financial Economics, Vol. 5, No. 2, 1977, pp. 177-188.

[7] J. C. Cox, J. E. Ingersoll and S. A. Ross, "A Theory of the Term Structure of interest Rates," Econometrica, Vol. 53, No. 2, 1985, pp. 385-407.

[8] S. J. Brown, P. H. Dybvig, "The Empirical Implications of the Cox, Ingersoll, Ross Theory of the Term Structure of Interest Rates," Journal of Finance, Vol. 41, No. 3, 1986, pp. 617-630.

[9] M. R. Gibbons and K. Ramaswamy, "A Test of the Cox, Ingersoll, and Ross Model of the Term Structure," Review of Financial Studies, Vol. 6, No. 3, 1993, pp. 619-658.

[10] G. Courtadon, "The Pricing of Options on Default-Free Bonds," Journal of Financial and Quantitative Analysis, Vol. 17, No. 1, 1982, pp. 75-100.

[11] A. Settari and K. Aziz, "Use of Irregular grid in Reservoir Simulation," Society of Petroleum Engineering Journal, Vol. 12, No. 2, 1972, pp. 103-114.

[12] G. Sorwar and G. Barone-Adesi, W. Allegretto, "Valuation of Derivatives Based on Single-Factor Interest Rate Models," Global Finance Journal, Vol. 18, No. 2, 2007, pp. 251-269. 


\section{Appendix}

$\left.\int_{s_{n-\frac{1}{2}}}^{s_{n+\frac{1}{2}}} \frac{\partial}{\partial s}\left(\Psi(s) \frac{\partial U}{\partial s}\right) d s \approx \Psi\left(s_{n+\frac{1}{2}}\right) \frac{\partial U}{\partial s}\right|_{s_{n+\frac{1}{2}}}-\left.\Psi\left(s_{n-\frac{1}{2}}\right) \frac{\partial U}{\partial s}\right|_{s_{n-\frac{1}{2}}}$

Further:

$$
\begin{aligned}
& \left.\frac{\partial U}{\partial s}\right|_{\substack{n+\frac{1}{2} \\
\frac{\partial U}{\partial s}}} \approx \frac{U_{n+1}^{m}-U_{n}^{m}}{s_{n+1}-S_{n}} \\
& \approx-\frac{1}{2}
\end{aligned}
$$

Substitution of the above approximation yields:

$$
\begin{aligned}
& \int_{s_{n-\frac{1}{2}}}^{s_{n+\frac{1}{2}}} \frac{\partial}{\partial s}\left(\Psi(s) \frac{\partial U}{\partial s}\right) d s \approx \frac{\Psi\left(s_{n+\frac{1}{2}}\right)}{s_{n+1}-s_{n}} U_{n+1}^{m}- \\
& {\left[\frac{\Psi\left(s_{n+\frac{1}{2}}\right)}{s_{n+1}-s_{n}}+\frac{\Psi\left(s_{n-\frac{1}{2}}\right)}{s_{n}-s_{n-1}}\right] U_{n}^{m}+\frac{\Psi\left(s_{n-\frac{1}{2}}\right)}{s_{n}-s_{n-1}} U_{n-1}^{m}}
\end{aligned}
$$

$$
\begin{gathered}
2 \Delta t \int_{s_{n-\frac{1}{2}}}^{s_{n+\frac{1}{2}}} \frac{s}{c^{2}(1-s)^{3}} f(s) Q(s) U d s \approx \\
2 \Delta t Q\left(s_{n}\right) U_{n}^{m} \int_{s_{n-\frac{1}{2}}}^{s_{n+\frac{1}{2}}} \frac{s}{c^{2}(1-s)^{3}} f(s) d s
\end{gathered}
$$

We further take:

$\int_{s_{n-\frac{1}{2}}}^{s_{n+\frac{1}{2}}} \frac{s}{c^{2}(1-s)^{3}} f(s) d s \approx \frac{s_{n}}{c^{2}\left(1-s_{n}\right)^{3}} f\left(s_{n}\right)\left(s_{n+\frac{1}{2}}-s_{n-\frac{1}{2}}\right)$

Similar approximation yields:

$$
\begin{aligned}
& 2 \int_{s_{n-\frac{1}{2}}}^{s_{n+\frac{1}{2}}} \frac{1}{c(1-s)^{2}} f(s) Q(s) U d s \approx \\
& 2 Q\left(s_{n}\right) U_{n}^{m} \frac{1}{c\left(1-s_{n}\right)^{2}} f\left(s_{n}\right)\left(s_{n+\frac{1}{2}}-s_{n-\frac{1}{2}}\right) \\
& 2 \int_{s_{n-\frac{1}{2}}}^{s_{n+\frac{1}{2}}} \frac{1}{c(1-s)^{2}} f(s) Q(s) U_{0} d s \approx \\
& 2 Q\left(s_{n}\right) U_{n}^{m-1} \frac{1}{c\left(1-s_{n}\right)^{2}} f\left(s_{n}\right)\left(s_{n+\frac{1}{2}}-s_{n-\frac{1}{2}}\right)
\end{aligned}
$$

